INTERNATIONAL JOURNAL OF SYSTEMATIC BACTERIOLOGY

Vol. 20, No. 4 October 1970

pp. $483-490$

\section{THE REIATIONSHIP OF CELL WALL COMPOSITION TO THE CURRENT CLASSIFICATION OF STAPHYLOCOCCI} AND MICROCOCCI

\author{
A. C. Baird-Parker
}

Unilever Research Laboratory, Colworth House Sharnbrook, Bedford, England

ABSTRACT. Structure and composition studies of cell walls of staphylococci and micrococci supports the classification of these organisms based on physiological and biochemical characters. Staphylococcus aureus and S. epidermidis are clearly separated as also are Micrococcus luteus and $M$. roseus.

The purpose of this contribution is to discuss the available information concerning the composition and structure of cell walls of staphylococci and micrococci in relation to the current classification of these organisms.

\title{
The Genus Staphylococcus
}

Members of the genus Staphylococcus are separated from members of the closely related genus Micrococcus by their ability to grow anaerobically and to ferment glucose (Evans, Bradford and Niven 1955; BairdParker 1963; Subcommittee 1965). Two species are currently recognized in this genus; these are Staphylococcus aureus and $\mathrm{S}$. epidermidis (Subcommittee 1969). Biochemical and phy siological characters separating these two species are shown in Table 1.

Staphylococcal cell walls contain two main components namely the multi-layered peptidoglycan and its associated teichoic acids. Small amounts of serologically distinct proteins and polysaccharides may also be present. The peptidoglycan consists of linear strands of a glycan consisting of repeating units of $\beta-1,4$ linked $\mathrm{N}$-acetyl-glucosamine and $\mathrm{N}$ acetyl-muramic acid residues that are linked through $\mathrm{N}$-acetyl-muramylL-alanine linkages to peptide subunits consisting of $\mathrm{N}^{\mathrm{a}}$ - ( L-alanyl-Disoglutamyl)-L-lysyl-D-alanine. These peptide subunits are cross-linked by peptide bridges containing solely or mainly glycine to form a threedimensional structure that is responsible forthe structural integrity of the cell wall. Where detailed studies have been done, these bridges have been shown to extend from the $\mathrm{N}^{\varepsilon}$-lysine residue of one peptide subunit to the C-terminal D-alanine of a neighboring peptide subunit. Although only a relatively few strains of staphylococci have been studied in sufficient detail to determine the composition and structure of the peptide bridges we are reasonably certain that in all staphylococcal cell walls the se bridges contain glycyl-glycine linkages as virtually all strains are lysed by lysostaphin endopeptidase (Klesius and Schuhardt 1968); this enzyme acts specifically on the glycyl-glycine linkages in the peptide bridges (Tipper and Strominger 1966). 
Table 1. Some differential characteristics of Staphylococcus species.

\begin{tabular}{lcc}
- & aureus & epidermidis \\
\hline Coagulases & + & + \\
Mannitol: acid aerobically & + & acid anaerobically \\
Endonucleases (heat resistant) & + & - \\
a toxin & + & + \\
Biotin for growth & - & + \\
\hline$d=$ some strains positive.
\end{tabular}

Structure and composition of Staphylococcus aureus cell walls

Cell walls of representatives of this species have been shown to contain organic phosphorus, ribitol, glucosamine, muramic acid and the amino acids, lysine, aspartic acid, serine, glycine, glutamic acid and alanine together with small amounts of threonine, proline, valine and leucine (Grove and Rude 1967a). These compounds can be accounted for in the 3 main components of the wall which are the peptidoglycan, the ribitol teichoic acids and the species specific precipitinogen Protein $\mathrm{A}$. Small amounts of other proteins and polysaccharides are also present. These correspond to the type specific agglutinogens and precipitinogens used in the serological typing of this species (Oeding 1965).

Peptidoglycan. This possesses the following features: 1) Approximately $50 \%$ of the $\mathrm{N}$-acetyl-muramic residues of the glycan are substituted with an acetyl-group on the 6-O position ( $T$ ipper and Strominger 1966), 2) All the N-acetyl-muramic residues are substituted by the tetrapeptide subunits (Ghuysen and Strominger 1963), 3) The peptide subunits are bridged by a species specific pentaglycine bridge.

Teichoic acids. Two serologically distinct ribitol-containing teichoic acids may be present; these are linear polymers containing either 4-O- $\beta$ or 4-O-a-N-acetyl-D-glycosaminyl-D-ribitol bridged by 1, 5 phosphodiester linkages. In $\underline{S}$. aureus strain Copenhagen the phosphodiester link of the teichoic acid has been shown to link the teichoic acid to the peptidoglycan (Ghuysen, Tipper and Strominger 1965). It appears to be uncertain whether the teichoic acid is linked to the N-acetyl-glycosamine or $\mathrm{N}$-acetyl-muramic acid part of the glycan (Ghuysen 1968). The $\beta$-linked teichoic acid corresponds to Polysaccharide $A$ and the $\alpha$ - and $\beta$-linked teichoic acids usually occur together in cell walls of a single strain although some strains contain only one or other of the teichoic acids; the $\beta$-linked teichoic acid occurs most commonly and is found in strains isolated from both human and animal sources (Marandon and Oeding 1967).

Protein A. This species specific agglutinogen is loosely bound to the cell wall and is probably attached to the peptidoglycan; it contains all the amino acids found in $\underline{S}$. aureus cell walls (Grove and Rude 1967b).

Structure and composition of Staphylococcus epidermidis cell walls

Cell walls of this species are similar in composition to those of $S$. aureus but contain glycerol in place of ribitol and most also contain glu$\overline{c o s e}$ in addition (Baird-Parker 1965). Two main components have been 
recognized, the se are the peptidoglycan and the teichoic acids; Protein A is absent from this species.

Peptidoglycan. The structure and composition of the peptidoglycan has only been studied in detail in a few strains (Tipper 1968; Petit, Strominger and Söll 1968; Schleifer, Reid and Kandler 1968). The glycan and peptide subunits appear to be similar in structure and composition to those of $S$. aureus. The peptide bridges are different, as they contain serine or L-alanine in addition to glycyl-glycine residues; serine can, however, be substituted for glycine in the bridge of $\mathrm{S}$. aureus by growth in the presence of serine (Tipper and Berman 1969). These are variable in composition with respect to the amount of glycine and amino acids they contain and also the position of the amino acids in the peptide chains; the average chain length is 5 amino acids. The position of the bridge in the two strains studied is the same as that in S. aureus peptidoglycan.

Teichoic acids. All teichoic acids that have been isolated so far from cell walls of this species contain glycerol. Depending on the linkage and carbohydrate attachment of the glycerol, four types of teichoic acids have been described. In these glycerol is either $a$ - or $\beta$-linked to glucose or a-linked to glucosamine; The teichoic acids containing glycerol $a$-linked to glucose may contain one or two glycosyl residues (Davison and Baddiley 1964; Davison et al. 1964; Oeding, Myklestad and Davison 1967; Archibald, Baddiley and Shaukat 1968). The teichoic acids are serologically distinct and may form a means of serologically typing this species. The a-linked glycosyl-glycerol teichoic acid probably corresponds to Carbohydrate $\mathrm{B}$ of Julianelle and Wieghard (Losnegard and Oeding 1963).

\section{The Genus Micrococcus}

Members of the genus Micrococcus are separated from staphylococci by their inability to grow anaerobically and to ferment glucose (BairdParker 1963). They are able to oxidize glucose with the production of acid or carbon dioxide and water. Five species are currently recognized in this genus. See Table 2 for physiological and biochemical characters separating these five species. The position of $M$. saprophyticus in the genus Micrococcus is controversial and on the grounds of similarity in DNA composition to the staphylococci the author has suggested that it should be classified as a subgenus of the genus Staphylococcus (Subcommittee 1971).

Unfortunately studies on the structure of cell walls of micrococci have been largely concentrated on the pigmented strains, i.e., M. luteus and M. roseus. However, we can assume that the structure and composition of the glycan is undoubtedly the same as that found in staphylococci. With the exception of strains of $M$. roseus all strains of micrococci that have been examined contain glycine in their cell walls (Salton and Pavlik 1960; Baird-Parker 1965); in M. luteus the glycine has been shown to be present in the peptide subunit. $\overline{\text { Als }}$ o with the exception of the few strains of $M$. saprophyticus that have been studied, all micrococci that have so fa $\bar{r}$ been tested are resistant to lysostaphin (Klesius and Schuhardt 1968). Therefore it is likely that peptide bridges containing glycyl-glycine links are 
Table 2. Some differential characters of Micrococcus species

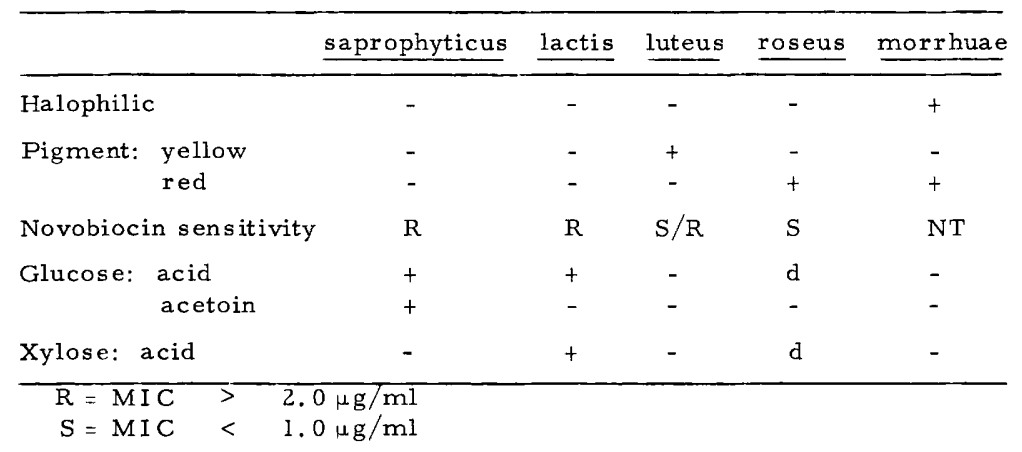

absent from cell walls of micrococci other than those of M. saprophyticus and that the glycine is substituted in the peptide subunit. Other components of the peptide subunit are probably identical to those found in the staphylococcal peptidoglycan namely L-alanine, D-alanine, D-glutamic acid and L-lysine.

It should be noted that a number of the organisms that have been misclassified in the genus Micrococcus contain the diamino acids, D. A.P. or ornithine, in their cell walls. None of these organisms are now considered to be members of this genus. The reasons for their exclusion have been discussed previously (Baird-Parker 1965). These organisms include "M. cinnabarius" and "M. rhodochrous" (Cummins and Harris 1956), ". $\overline{\mathrm{M}}$. halodenitrificans" (Takahashi and Gibbons 1959), "M. varians"

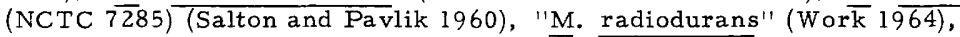
"M. denitrificans" and Abd-El-Malek and Gibson's group 3b micrococci (Baird-Parker 1965).

Structure and composition of cell walls of Micrococcus saprophyticus

Cell walls of this species contain giucose, ribitol or glycerol, glucosamine, muramic acid, galactosamine (some strains), alanine, glutamic acid, glycine, lysine, aspartic acid and serine (Salton and Pavlik 1960; Baird-Parker 1965).

Peptidoglycan. Detailed studies of the peptidoglycan have not been done; the likely presence of glycine in the peptide bridges has been discussed above. It may be relevant in considering the taxonomic position of this species that it is highly resistant to novobiocin whereas strains of staphylococci with the exception of certain hospital strains of S. aureus, are highly sensitive to this antibiotic (Mitchell and Baird-Parker 1967; Jeffries 1968). Novobiocin affects cell wall synthesis although its primary action is probably not against cell walls (Wishnow et al. 1965).

Teichoic acids. Two types of teichoic acid have been reported in the small number of strains of this species that have been studied. Cell walls of the type strain of the species (NCTC 7292) contain ribitol that is probably $\beta$-linked to glucosamine; this teichoic acid is serologically identical to the $\beta$-linked ribitol glucosamine teichoic acid of $S$. aureus (Polysaccharide A) (Davison et al. 1964). It is of interest that strains of $\mathrm{M}$. saprophyticus containing ribitol (these mainly correspond to Bair $\bar{d}$-Parker's 
Micrococcus subgroup 3) are able to cause infections of urinary tract (Roberts 1967). The other type of teichoic acid contains glycerol linked to glucose.

Structure and composition of Micrococcus lactis cell walls

Cell walls are similar in composition to those of $M$. saprophyticus but some strains contain two additional sugars, i. e., mannose and galactose (Baird-Parker 1965).

Peptidoglycan. The structure of the peptidoglycan is not known but it is probably similar to that of $M$. luteus. Cells of this species like those of $M$. saprophyticus are highly resistant to novobiocin.

Teichoic acid. This species contains a variety of glycerol or ribitol teichoic acids that are linked to glucose, glucosamine ot galactosamine (Davison and Baddiley 1963; Baddiley et al. 1968). In one strain studied, the teichoic acid was extremely complex and contained glucose, glucosamine, and galactosamine. Certain strains of Micrococcus lactis contain polysaccharides containing neither ribitol nor glycerol (Baddiley et al. 1968).

Structure and composition of cell walls of Micrococcus luteus

The composition of cell walls of this species appears to be similar to those of strains of $\mathrm{M}$. saprophyticus and $\mathrm{M}$. lactis except that teichoic acids would always appear to be absent (Davison and Baddiley 1963; Baird-Parker 1965). Many strains of this species are sensitive to lysozyme and novobiocin but some strains are resistant (Jeffries 1968).

Peptidoglycan. The peptodiglycan of "M. lysodeikticus," which is a typical member of this species, has been studied in considerable detail; see Ghuysen (1968). The recent studies by Campbell, Leyh-Bouille and Ghuysen (1969) on further representatives of the species, namely strains labelled Sarcina lutea, Micrococcus flavus and M. citreus show that these organisms have the same peptidoglycan structure as $\overline{\mathrm{M}}$. lysodeikticus. This provides further evidence to support the current view that all these organisms are members of the same species (M. luteus). The peptide subunits of the glycan possess the structure Na-(L-alanyl- $\gamma$ ( $a-D$-glutamylglycine)) - L-lysyl-D-alanine. This is identical in structure to the peptide subunits of staphylococci except that the a carboxyl group of the glutamic acid residue is substituted with glycine. Further differences from cell walls of staphylococci is that not all the $\mathrm{N}$-acetyl-muramic residues are peptide substituted and $O-a c e t y l$ substitution of the muramic acid is uncommon; see Ghuysen (1968). The question of the type of bridge between the peptide subunits has been controversial for a number of years although it now appears that this controversy has been finally resolved. It would appear that the peptide subunits are polymerised by bridges formed by direct bonding between the peptide subunits. Two types of cross-1inking are involved. (1) $\mathrm{N}^{\varepsilon}-(\mathrm{D}$-alanyl)-L-lysine linkages between the $\varepsilon$ amino group of the lysine molecule of one peptide subunit to the C-terminal Dalanine of a neighbouring peptide unit and (2) D-alanyl-L-alanine linkages between the $\mathrm{N}$-terminal alanine of one peptide subunit to the $\mathrm{C}$-terminal alanine of a neighbouring unit; in the organisms studied by Campbell et al. (1969) the latter type of linkage predominated.

Polysaccharides. In "M. lysodeikticus" ( $\mathrm{M}$. luteus) the polysaccharide consists of a polymer containing glucose and $\overline{2}$-acetamido-2-deoxymannuronic acid (Perkins 1963). Other polysaccharides occur in other 
organisms of this species; see Baddiley et al. (1968). According to Campbell et al. (1969) it is probable that the glycan strands consist of 8-18 disaccharide units linked through one muramic acid phosphate to a polysaccharide consisting of 10 glucose residues together with the further carbohydrates making up the polysaccharide.

Structure and composition of cell walls of Micrococcus roseus

The outstanding feature of the composition of cell walls of these organisms is that both glycine and teichoic acids are absent.

Peptidoglycan. The glycan and peptide subunits of this molecule are identical to those found in staphylococci. It differs, however, from peptidoglycan of staphylococci in that the peptide bridge contains only Lalanine or L-alanine and L-threonine. The proposed structure of this bridge is $\mathrm{N}^{\mathcal{E}}$ (L-alanyl-L-alanyl-L-alanyl- L-threonine)-L-lysine; in a threonine negative mutant, threonine is absent from the bridge (Petit, Munoz and Ghuysen 1966).

Polysaccharides. Cell walls of this organism contain glucose, galactose and mannose (Baird-Parker 1965). The structure of the polysaccharide has not been determined.

Micrococcus morrhuae. No information is available concerning the composition or structure of cell walls of this organism.

\section{CONCLUSIONS}

Current information relating to the structure and composition of cell walls of staphylococci and micrococci mainly supports the classification of these organisms based on physiological and biochemical characters. Staphylococci possess cell walls which axe distinct from those of micrococci. The two species currently recognized within the genus Staphylococcus are clearly separated by differences in their cell wall composition.

Further work is required to determine the composition and structure of cell walls of micrococci. We have evidence that $M$. lactis and $M$. saprophyticus have distinct cell wall peptidoglycans and we know that the teichoic acids present in these strains are extremely complex indicating that further division of these two species may be possible on serological grounds. The peptidoglycans of the two best defined species of micrococci, i. e. M. roseus and $M$. luteus (Evans 1965), are quite distinct.

I hope that further studies will be done on cell walls of the type strains of $M$. saprophyticus, $M$. lactis and $M$. morrhuae as such studies would be extremely valuable in finding further information concerning the taxonomic position and validity of these species.

\section{REFERENCES}

Archibald, A.R., J. Baddiley and G.A. Shaukat. 1968. The glycerol teichoic acid from walls Staphylococcus epidermidis 12. Biochem. J. 110:583.

Baddiley, J., J.H. Brock, A. L. Davison and M. D. Partridge. 1968. The wall composition of micrococci. J. gen. Microbiol. 54:393.

Baird-Parker, A.C. 1963. A classification of micrococci and staphylococci based on physiological and biochemical tests. J. gen. Microbiol. 30: 409 .

- 1965. The classification of staphylococci and micrococci from world-wide sources. J. gen. Microbiol. 38:363. 
Campbell, J.N., M. Leyh-Bouille and J. M. Ghuysen. 1969. Characterization of Micrococcus lysodeikticus type of peptidoglycan in walls of other micrococcaceae. Biochemistry 8:193.

Cummins, C.S. and H. Harris. 1956. The chemical composition of the cell wall in some Gram-positive bacteria and its possible value as a taxonomic character. J. gen. Microbiol. 14:583.

Davison, A. L. and J. Baddiley. 1963. The distribution of teichoic acids in staphylococci. J. gen. Microbiol. 32:271.

and - 1964. Glycerol teichoic acids in walls of Staphylococcus epidermidis. Nature, London, 202:874. , T. Hofstad, N. Losnegard and P. Oeding. 1964. Teichoic acids in walls of staphylococci. Serological investigations on teichoic acids from walls of staphylococci. Nature, London, 202:872.

Evans, J. B. 1965. Current views and problems relating to the taxonomy of the Micrococcaceae. Int. Bull. Bact. Nomen. Taxon, 15:111.

, W. L. Bradford and C.F. Niven, Jr. 1955. Comments concern-

ing the taxonomy of the genera Micrococcus and Staphylococcus. Int. Bull. Bact. Nomencl. Taxon. 5:61.

Ghuysen, J. M. 1968. Use of bacteriolytic enzymes in determination of wall structure and their role in cell metabolism. Bact. revs. 32:425. and J. L. Strominger. 1963. Structure of the cell wall of Staphylococcus aureus, strain Copenhagen. II. Separation and structure of disaccharides. Biochemistry 2:1119.

D.G. Tipper and J. L. Ströminger. 1965. Structure of cell wall of Staphylococcus aureus strain Copenhagen. IV. The teichoic acid glycopeptide complex. Biochemistry $4: 474$.

Grove, A. and S. Rude. 1967a. Immunochemical characterization of Staphylococcus aureus cell walls. Acta path. et microbiol. scandinav. 71:409.

Jeffries, L. 1968. Sensitivity to novobiocin and lysozyme in the classification of micrococcaceae. J. appl. Bact. 31:436.

Klesius, P.H. and V.P. Schudardt. 1968. Use of lysostaphin in the isolation of highly polymerized deoxyribonucleic acid and in the taxonomy of aerobic micrococcaceae. J. Bact. 95:739.

Losnegard, N. and P. Oeding. 1963. Immunochemical studies of polysaccharides from Staphylococcus epidermidis. 2. Antigenic properties. Acta path. et microbiol. scandinav. 58:493.

Marandon, J. L. and P. Oeding. 1967. Investigation of animal Staphylococcus aureus strain 2. Antigens. Acta path. et microbiol. scandinav. $\overline{70: 300 .}$

Mitchell, R. G. and A.C. Baird-Parker. 1967. Novobiocin resistance and the classification of staphylococci and micrococci. J. appl. Bact. 30:251.

Oeding, P. 1965. Antigenic properties of staphylococci. Ann. N.Y. Acad. Sci. 128:183.

, B. Myk $\overline{l e s} t a d$ and A. L. Davison. 1967. Serologic investigations on teichoic acids from walls of Staphylococcus epidermidis and Micrococcus. Acta path. et microbiol. scandinav. 69:458.

Perkins, H. R. 1963. A polymer containing glucose and amino-hexuronic acid isolated from cell walls of Micrococcus lysodeikticus. Biochem. J. $86: 475$. 
Petit, J.F., E. Munoz and J.M. Ghuysen. 1966. Peptide cross-links in bacterial cell wall peptidoglycans studied with specific endopeptidases from Streptomyces albus G. Biochemistry $5: 2764$.

, J.L. Strominger and D. Söll. 1968. Biosynthesis of the peptidoglycan of bacterial cell walls. VII. Incorporation of serine and glycine in the interpeptide bridge of Staphylococcus epidermidis. J. biol. Chem. 243:757.

Roberts, A.P. 1967. Micrococcaceae from the urinary tract in pregnancy. J. clin. Path. 20:631.

Salton, M.R.J. and J.G. Favlik, 1960. Studies of the bacterial cell wall. VI. Wall composition and sensitivity to lysozyme. Biochim. biophys. Acta 39:398.

Schleifer, K.H., M. Reid and O. Kandler, 1968. The amino acid sequence of the murein of Staphylococcus epidermidis. Arch. Mikrobiol. 62:198.

Subcommittee on Taxonomy of Staphylococci and Micrococci. 1965. Recommendations. Int. Bull. Bact. Nomen. Taxon. 15:109. - Minutes of Third Meeting, 1971. Intl. J. Syst. Bact. (In press)

Takahashi, I. and N.E. Gibbons. 1969. The effect of salt concentration in the morphology and chemical composition of Micrococcus halodenitrificans. Canad. J. Microbiol. 5:25.

Tipper, D.J. 1968. Federation Proc. p. 242. and J. L. Strominger. 1966. Isolation of 4-O- $\beta-\mathrm{N}-$ acetyl muramyl$\mathrm{N}-$ acetylglucosamine and 4-O- $\beta-\mathrm{N}, 6-\mathrm{O}$ diacetylmuramyl-N-acetylglycosamine and the structure of the cell wall polysaccharide of Staphylococcus aureus. Biochim. biophys. Acta 22:48.

and M.F. Berman. 1969. Structure of the cell wall peptidoglycan of Staphylococcus epidermidis Texas 26 and Staphylococcus Copenhagen. Biochem istry $8: 2 \overline{183}$.

Work, E. 1964. Amino acids of walls of Micrococcus radiodurans. Nature, London, 201:1107.

Wishnow, R. M., J. L. Strominger, C.N. Birge, and R.H. Threnn. 1965. Biochemical effects of novobiocin on Staphylococcus aureus. J. Bact. 89:1117. 